\section{Decisions spared}

\section{R. V. Jones}

Hitler's Uranium Club: The Secret Recordings at Farm Hall. Edited by Jeremy Bernstein. American Institute of Physics: 1995. Pp. 427. £25.

For the last six months of 1945 , ten German physicists were held in isolated but gentle detention at a country house, Farm Hall, some 20 miles northwest of Cambridge in England. They had been taken there, following the collapse of Germany, because they were believed to have been concerned in the exploitation of nuclear fission as a means of making an 'atomic' bomb. Unknown to them, their conversations were monitored and recorded because of the light they might throw on how near the Germans had come to making a bomb.

Transcripts of the conversations were regularly sent under highest secrecy to the authorities responsible for nuclear development in the United Kingdom and the United States. These transcripts, extracts from which were quoted by General Leslie Groves and Samuel Goudsmit in their subsequent books, were kept secret until 1992, when the Lord Chancellor (Lord Mackay), at the request of representatives of the Royal Society and the British Academy, ruled that they could at last be made public.

It was further decided that the full transcripts should be published (and translated where necessary) by the Institute of Physics in the United Kingdom with an introduction by F. C. Frank, who had not only read the transcripts at the time they were made but had also visited the detainees at Farm

\begin{tabular}{|l|}
\hline \multicolumn{1}{|c|}{ A Bedside Nature } \\
Heisenberg's account of Germany's \\
failure to produce a nuclear bomb is one \\
of many contributions about science and \\
scientists during and after the war that \\
appear in the recently published $A$ \\
Bedside Nature: Genius and Eccentricity in \\
Science 1869-1953 edited by Walter \\
Gratzer with a foreword by Stephen Jay \\
Gould. This paperback anthology \\
"presents a panorama of science seen \\
against the backdrop of nineteenth- and \\
twentieth-century history, with its \\
triumphs, débâcles, surprises and \\
absurdities". Macmillan, £19.95, $\$ 29.95$ \\
(nonsubscribers); $£ 14.95, \$ 24.50$ \\
(subscribers). Further details available \\
from Nature on $+44(0) 1718434962$ \\
(telephone).
\end{tabular}

Hall and had known some of them in Germany before 1939 . The resulting book was published by the Institute of Physics in 1993 under the title Operation Epsilon: The Farm Hall Transcripts, and the University of California Press sold and distributed it in the United States (for a review see Nature 364, 114; 1993).

Frank's introduction and comments have so much authority that there hardly seems need for a second book on the same subject; but this is what we now have in Jeremy Bernstein's Hitler's Uranium $C l u b$, which gives the same transcripts but with an extended commentary for readers who do not have the "considerable technical background" that Bernstein deems

mates of the necessary amount of uranium-235 suggested that it was far beyond anything they could hope to achieve*. This is what British and American physicists would also have decided, had it not been for the vital contribution of Rudolf Peierls and Otto Frisch in Birmingham, who showed that the required amount of uranium-235 might be within the bounds of feasibility. The effort needed, although Herculean, was successfully achieved by American engineers under the leadership of General Groves.

The question has often been asked: why did the Germans not succeed in making an atomic bomb? It would be far too crude to reply that this was because they had neither Peierls and Frisch, nor Groves. But it is worth remarking that Peierls and Frisch had both come to England as "birds of passage" in flight from the Nazis. And it is also worth remarking that the motivation in the United Kingdom was far greater than that in Germany. In 1940, I can recall James Tuck in the Cabinet Office saying to me that the atomic bomb, if only we could make it, seemed our one hope of winning against Germany.

On the other side, at least until 1942, there was no such desperation in Germany, and there seemed no need for German physicists, even those

necessary for a full appreciation of both the transcripts and Frank's introduction.

What Bernstein has therefore provided is a running commentary on the transcripts themselves, supplemented by sketches of the historical, scientific and social backgrounds to the statements made by the detainees to one another. $\mathrm{He}$ has added further interest by including a diary by one of the detainees, Erich Bagge, and letters from another, Max von Laue, to Paul Rosbaud. The transcripts provide a unique insight into the characters, relationships and thoughts of a remarkable group of individuals, nearly all deeply involved in nuclear developments in wartime Germany, at the very time when they were told the news of the bomb on Hiroshima.

They were stunned - in Werner Heisenberg's case so much that in estimating the amount of uranium-235 that must have been needed for a bomb, he could at first resort only to a 'back of the envelope' calculation pathetically cruder than any he may himself have made earlier in the war. Within a few days, though, he had recovered sufficiently to produce a better understanding of what the Allied physicists had achieved.

The transcripts show that the Germans had given up the prospect of making a bomb in 1942, mainly because their esti- who wanted to win the war, to question Heisenberg's estimate that pointed to the unfeasibility of bomb production in the foreseeable future. And although the alternative approach to a bomb through plutonium had been suggested by both Carl Friedrich von Weizsäcker and Fritz Houtermans, this was not followed up; and the most that was done after 1942 was towards a source of heat for a "boiler".

Naturally, as they recovered from their first shock, the Farm Hall detainees began to ask why they had failed so signally. Reproaches went so far as Otto Hahn (who had refrained from working towards a bomb) saying to Heisenberg "At any rate, Heisenberg, you're just second-raters and you may as well pack up", to which Heisenberg replied "I quite agree". Later in the same discussion, von Weizsäcker offered: "I believe the reason we didn't do it was because all the physicists didn't want to do it on principle. If we had all wanted Germany to win the war we could have succeeded."

This comment could readily be construed as 'sour grapes', but it could have contained a pip of truth in that there was no such intense motivation in Germany as had led, for example, to microwave radar

*See for example I. M. Klotz's review of Nazi Science by Mark Walker in Nature 379, 410 (1996). 